\section{A Ground-based Comparison of Nutrient Delivery Technologies Originally Developed for Growing Plants in the Spaceflight Environment}

\author{
D. M arshall Porterfield, ${ }^{1}$ \\ Thomas W. D reschel, ${ }^{2}$ and \\ M ary E. M usgrave ${ }^{1}$
}

AdDitional indeX words. porous tube plant nutrient delivery system, phenolic foam, nutrient pack

Summary. A ground-based comparison of plant nutrient delivery systems that have been developed for microgravity application was conducted for dwarf wheat (Triticum aestivum L. 'Yecora R ojo') and rapidcycling brassica (Brassica rapa $L$. CrG C\#1-33) plants. These experiments offer insight into nutrient and oxygen delivery concerns for greenhouse crop production systems. The experiments were completed over a 12-day period to simulate a typical space shuttle-based spaceflight experiment. The plant materials, grown either using the porous-tube nutrient delivery system, the phenolic foam support system, or a solidified agar nutrient medium, were compared by plant-growth analysis, root zone

We would like to thank the L ouisiana State U niversity Agricultural C hemistry D epartment for help with the elemental composition analysis, and John Kovar, Agronomy Department, Louisiana State U niversity, for help with root morphometry. This project was funded by N ASA (Space Biology grant N AGW-3759 to $M E M$ and $G$ raduate Student Researcher Fellowship NGT-51097 to DM P). Approved for publication by the director of the L ouisiana Agricultural Experiment Station as paper \#97-38-0174. The cost of publishing this paper was defrayed in part by the payment of page charges. U nder postal regulations, this paper therefore must be hereby marked advertisement solely to indicate this fact.

${ }^{1} \mathrm{D}$ epartment of Plant Pathology and C rop Physiology, L ouisianaStateU niversity Agricultural C enter, L ouisiana State U niversity Agricultural Experiment Station, Baton Rouge, LA 70803.

${ }^{2}$ D ynamac Corporation, Kennedy Space Center, FL 32899. morphological measurements, elemental composition analysis, and alcohol dehydrogenase enzyme activity assay. The results of these analyses indicate that the porous tube plant nutrient delivery and the phenolic foam systems maintain plant growth at a higher level than the solidified agar gel medium system. R oot zone oxygenation problems associated with the agar system were manifested through biochemical and morphological responses. The porous tube nutrient delivery system outperformed the other two systems on the basis of plant growth analysis parameters and physiological indicators of root zone aeration. This information is applicable to the current crop production techniques used in greenhousecontrolled environments.

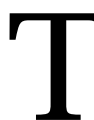

o determine microgravity effects on plants, a nutrient delivery system must be developed that performs in a manner that minimizes secondary effects of microgravity plant culture. O ne major concern in the development of a nutrient delivery system for use in space is avoiding oxygen deprivation in the root zone caused by inhibition of convectivefluid movement asso ciated with microgravity. This problem is compounded in conventional rooting media, which tend to keep roots too wet in microgravity because water does not drain in the absence of the gravity vector. Thismay explain why researchers have tended to use media that maintain fairly even water distribution (such as agar and phenolic foam) for supporting plant growth during shortterm shuttle flights (H eyenga, 1994; Kordyum et al., 1983; Krikorian and Levine, 1992; Kuang et al., 1995; Levine and Krikorian, 1992).

While these less complex, passive media systems have been used to grow plants for short-term spaceflight experiments ( 7 to $15 \mathrm{~d}$ ), they are considered incapable of being adapted for continuous, long-term use in abioregenerativelifesupport system (BLSS). Advanced hydroponic technologies are being developed that will meet the rigorous demands of spaceflight. $\mathrm{H}$ ydroponic techniques are considered to have many advantages over soil culturefor space-based BL SS applications, including reduced water and nutrient use, rapid crop turnover, facilitation of automation, and reduced volume requirements. The problem with traditional hydroponics is that it relies on gravity for solution flow ( $\mathrm{H}$ alstead and Dutcher, 1984). The porous-tube plant nutrient delivery system (PTPN D S) (D reschel et al., 1994) was initially developed at Kennedy Space Center as part of the BLSS research program. The PTPNDS can provide hydroponic culture of plants in microgravity becausetheflow of nutrient solution within the system is not dependent on gravity. This technology has been shown to avoid the problemsassociated with containing a solution in the microgravity environment (Johnson et al., 1995).

The PTPNDS(Fig. 1) usesatube constructed of a porous ceramic material surrounded by an opaque nonporous material that contains and protects the roots from light and desiccation. The amount of nutrient solution available to the roots can becontrolled by varying the internal pressure of the tube. The PTPNDS is a candidate nutrient delivery technology for new plant growth systems being developed for space station application. To evaluate the success of this system in supporting plant growth, it is necessary to determine how plants respond physiologically to this nutrient delivery system as compared to other types that have been used for spaceflight applications. D warf wheat and rapid-cycling brassica plantsgrown on the PT PN DS were compared to those grown on the agar-solidified gel nutrient medium

Fig. 1. Schematic diagram showing the basic configuration of the porous tube plant nutrient delivery system.

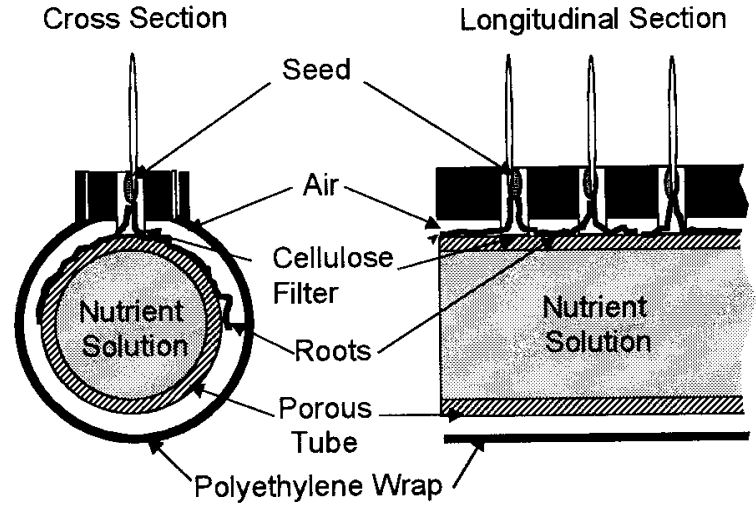


Cross Section

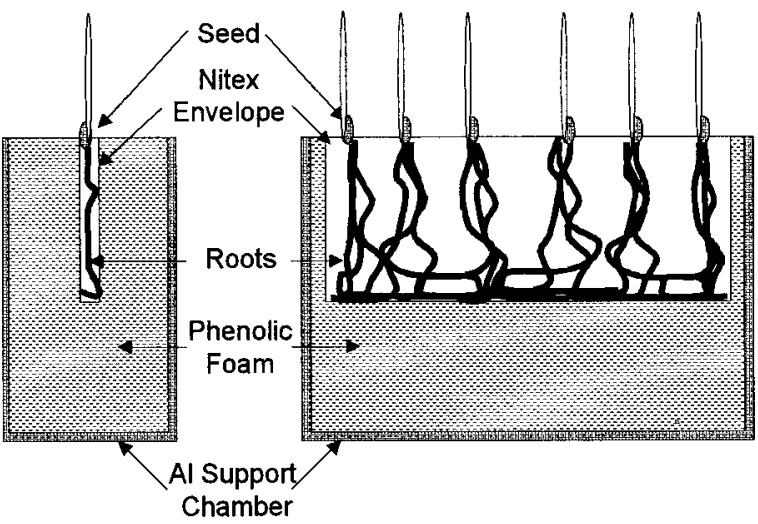

phological changes that occur with reduced oxygen. The plant-growth analysis data also allow a better understanding of how overall growth may be affected by the environment encountered by the root system.

\section{Materials and methods}

Plant material. These experiments were conducted with both a

Fig. 2. Schematic diagram showing the basic configuration of the phenolic foam plant nutrient delivery system.

(H eyenga, 1994; Kordyum et al., 1983; Kuang et al., 1995) and nutrient-saturated phenolic foam (Cowles et al., 1984; Krikorian and Levine, 1992), both of which have been used for space shuttle-based lifesciencesmicrogravity research. These plant species were chosen because of their acceptance within the life sciences space research community and because they are candidatesfor the first spaceflight test of the PTPNDS.

These experimentswere designed to simulate a typical shuttle based experiment lasting between 7 and $15 \mathrm{~d}$ with no crew interaction. The nutrient delivery systems were compared by analysis of rootzonemorphology, root alcohol dehydrogenase (ADH) activity, root and shoot nutrient content, and general growth parameters of plants. Rootzonemorphology of dwarf wheat plants was determined by digital image analysis of scanned root images. Plant-growth analysis was performed to monitor changes in overall plant growth, and elemental content of plant tissue was examined by ICP analysis (inductively coupled plasma spectroscopy). ADH activity wasmeasured asa metabolic indicator of oxygen availability to the roots. The collective data give an overall assessment of the performance of the PTPNDS as compared to techniques currently used for short-term plant research aboard the space shuttle, and provide important baseline information for interpreting the results of previous spaceflight experiments. The results also identify any asso ciation between ADH activity and the appearance of root zone mor- monocot and a dicot species: dwarf wheat and rapid-cycling brassica. For all of the experiments discussed below four samples of six plants (24 total) were grown for $12 \mathrm{~d}$ and the experiment was replicated three times with each species. The dwarf wheat seeds were air-imbibed in a high humidity chamber for $3 \mathrm{~d}$ before planting (in order to synchronizegermination) and the rapid-cycling brassica seeds were planted dry.

Nutrient delivery systems. A modified half-strength $\mathrm{H}$ oagland solution (H oagland and Arnon, 1950) was made using deionized water to contain the following macronutrients: $6 \mathrm{~mm} \mathrm{~N}, 2.6 \mathrm{~mm} \mathrm{~K}, 2 \mathrm{~mm} \mathrm{Ca}, 1 \mathrm{~mm}$ $\mathrm{Mg}, 1 \mathrm{~mm} \mathrm{~S}$, and $0.6 \mathrm{~mm} \mathrm{P}$. The micronutrients used were $\mathrm{Fe}, \mathrm{B}, \mathrm{M} \mathrm{n}$ $\mathrm{Zn}, \mathrm{Cu}$, and $\mathrm{M} \mathrm{O}$ at $54,35,6.7,0.58$, 0.24 , and $0.07 \mathrm{~mm}$ respectively. The $\mathrm{pH}$ of this solution was adjusted to 6.0 .

The PTPNDS was constructed from a 2.1-cm (0.83-inch) outside diameter hydrophilic porous ceramic filter tube( $M$ illiporeC $0 .$, Bedford, M ass.) with a functional pore size of $0.7 \mathrm{~mm}$ $\left(2.76 \times 10^{-5} \mathrm{inch}\right)$. Theporoustubewas wrapped with a polyethylene film material that was whiteon theoutsidesurface and black on the inside surface. This material served as a barrier to both light and water vapor, and was attached to a polypropylene seed holder by Velcro. This wrap formed a root containment volume of $0.7 \mathrm{~cm}^{3} \cdot \mathrm{cm}^{-1}$ ( 0.107 inch $^{3} /$ inch) of porous tube. A peristaltic pump was used to circulate nutrient solution through each of the two 25-cm (9.8-inch) long porous tubes, in parallel, at a rate of $0.1 \mathrm{~L} \cdot \mathrm{min}^{-1}(0.026 \mathrm{gal} / \mathrm{min})$ from a 0.325-L (0.086-gal) reservoir. Each tube had two seed holders, accommodating six seed sapiece. E ach of the 24 seeds planted was held in place by a cellulose filter (C at. \# 23534B, Rainin Inst. Co., Woburn, M ass.).

For thephenolic foam system (Fig. 2) $\mathrm{O}$ asis Rootcube (Smithers- $\mathrm{O}$ asis, Kent, O hio) was cut into blocks, inserted into an al uminum support chamber (ASC) $(9.8 \times 4.1 \times 6.5 \mathrm{~cm}$ inner dimensions) (3.86 $\times 1.61 \times 2.56$ inch), and equipped with a $9.0 \times 6.0 \mathrm{~cm}$ (3.54 $\times 2.36$ inch) N itex (Small Parts, Inc., M iami Lakes, Fla.) ( $35 \mathrm{~mm}$ pore size) $\left(1.38 \times 10^{-3}\right.$ inch) envelope according to Levine and Krikorian (1992). Four ASC bases were used to plant 24 seeds with six seeds per $\mathrm{N}$ itex envelope. $\mathrm{H}$ alf-strength $\mathrm{H}$ oagland's nutrient solution $(150 \mathrm{~mL})(5.1 \mathrm{fl} \mathrm{oz})$ was added to each ASC.

Agar gel nutrient medium technique (Fig. 3 ) is based on an $0.8 \%$ agar solution made from half-strength $\mathrm{H}$ oagland's nutrient medium. This solution was prepared and autoclaved, and after cooling was poured into plastic film cubes $(4.5 \times 4.2 \times 6.5 \mathrm{~cm})$ $(1.77 \times 1.65 \times 2.56$ inch $)$ made from Sun Bags (Sigma, St. Louis, M 0.) using an impulse sealer ( $\mathrm{H}$ eyenga, 1994). The bags were precut to include three $1.0-\mathrm{cm}(0.39$-inch) diameter holes spaced $0.5 \mathrm{~cm}$ (0.197 inch) apart on the top face. Each of four ASC bases supported two bags, which were secured using tape. The bags were filled with at least $135 \mathrm{~mL}(4.6 \mathrm{fl} \mathrm{oz})$ of autoclaved agar nutrient solution, which was allowed to solidify. Three microcentrifuge tubes, modified by

Fig. 3. Schematic diagram showing the basic configuration of the agar gel plant nutrient delivery system.

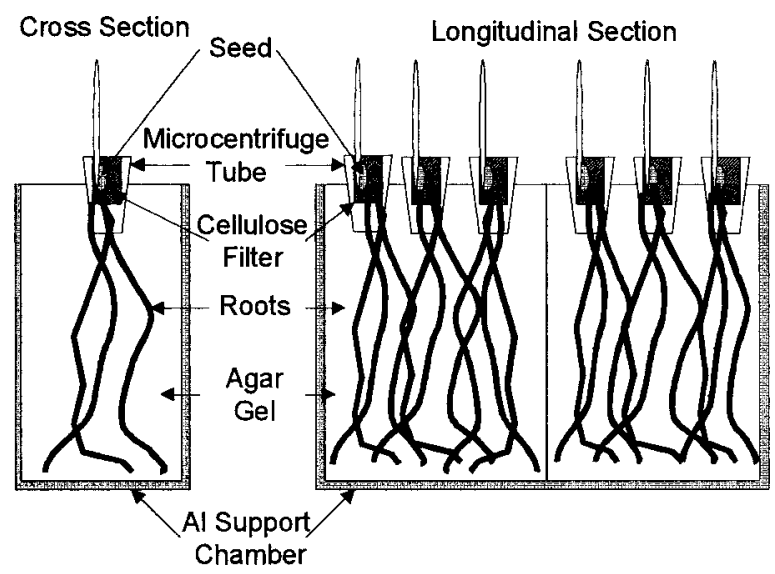




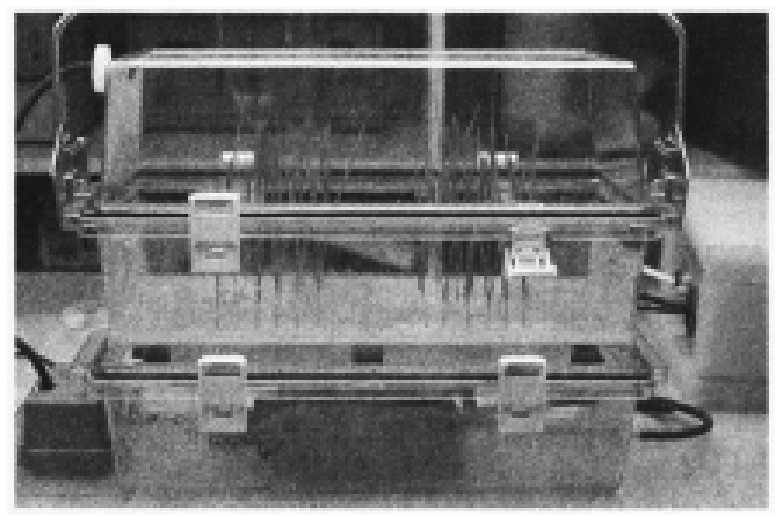

situated peristaltic pump. The phenolic foam and agar systems were mounted in theN D SH C by cutting four $9.7 \times 4.0$ $\mathrm{cm}(3.8 \times 1.6$ inch) openings in the wall separating the upper and lower chambers. The ASC bases were held in place just under these openingsusing elastic silicone tubing.

\section{Plant growth} ANALYSIS. To describe the

Fig. 4. D warf wheat plants growing on the porous tube plant nutrient delivery system maintained inside of a nutrient delivery system housing chamber.

cutting off the bottom $1 \mathrm{~cm}(0.39$ inch) were placed into each of the threeholes and used to hold a cellulose filter containing a seed. A total of 24 seeds was planted in the agar system.

Each of the nutrient delivery systems used in this study was housed in an individual, clear, polycarbonate chamber. These nutrient delivery system housing chambers (N D SH C) were constructed from two $\mathrm{N}$ algene $\mathrm{Bio}$ Transport Carrier chambers ( $C$ at. \#7137; N algeneN U N C I nternational, Rochester, N.Y.) by cutting off thetop of one Bio Transport Carrier System chamber and adhering with cement another B io T ransport Carrier System chamber on top. This effectively produced a double chamber: an upper shoot chamber and a lower nutrient delivery chamber (Fig. 4). Culture was maintained in the presence of air flow $\left(300 \pm 11 \mathrm{~mL} \cdot \mathrm{min}^{-1}\right)\left(18 \pm 0.66 \mathrm{inch}^{3} /\right.$ min), produced by aquarium air pumps (Penn Plax 1550; Penn-Plax, Inc., Carden City, N.Y.), filtered by the use of $\mathrm{N}$ algene micropore filters ( $\mathrm{C}$ at. \# 199-2020). The porous tube system was adapted to the housing chamber by directly mounting the seed holders to the wall separating the upper and lower chambers and drilling holes in the wall that corresponded with the holes in the seed holder to allow the shoots to pass into the top chamber. Thetubeswereheld in placeunder the seed holder by the velcro fasteners on the tube wraps to the seed holders. Thelower root portion of theN D SH C also contained the porous tube nutrient solution reservoir, but solution flow was produced by an externally
(M arkwell et al., 1978), and for alcohol dehydrogenase (ADH ) activity by the spectrophotometric measurement of NADH oxidation at $339 \mathrm{~nm}$ (D augherty and M usgrave, 1994). The ADH data were analyzed using oneway AN OVA and by Duncan's multiple range test at the 0.05 significance level using the statistical analysis tools of $\mathrm{M}$ icrosoft Excel.

ROOT SYSTEM MORPHOMETRICS. Four samples of six dwarf wheat plants each were taken at 3-d intervals following initiation of theexperiment. E ach plant wascarefully removed from the system so that intact root systems were available for analysis. This analysis could not be conducted on the rapid-cycling brassica plants due to the extensive interweaving of the fine roots that prevented complete removal of intact root systems.

While floating in a clear tray filled with water, each root system was scanned by a desk jet scanner ( $\mathrm{H}$ ewlettPackard, Palo Alto, C alif.) at 300 dots/ inch using $\mathrm{H}$ ewlett Packard Scanware software in line art mode. This effectively produced an image of black roots on a white background. Background imagenoisewas removed using Z-Soft Photofinish software (Zsoft Corp., $M$ arietta, $G$ a.). Each of the root systems was partially cut up before scanning to minimize root overlap. The resulting images were analyzed on the basis of length and average width using R ootlaw software (Pan and Bolton, 1991). L ateral surface area was calculated using the standard formula describing surface area of a cylinder $(\Pi \times$ $\mathrm{d} \times \mathrm{I}$; where $\mathrm{d}$ is the diameter, and $\mathrm{I}$ is the length), and all data were analyzed using two-way ANOVA and by Duncan's multiple range test at the 0.05 significance level using the statistical analysis tools add-in component of $\mathrm{M}$ icrosoft Excel.

Elemental composition analysis. $D$ warf wheat tissuenutrient levelswere determined by elemental composition

Table 1. C alculation of plant growth analysis values, where $\mathrm{W}=$ total dry weight, $\mathbf{T}=$ time in days, $A=$ leaf area, $S=$ shoot dry weight, $R=$ root dry weight.

\section{Plant growth parameter}

Change in weight $(\Delta \mathrm{W})$

Relative growth rate (RGR)

$\mathrm{N}$ et assimilation rate (N AR)

Root weight ratio

Specific shoot weight

\section{Formula}

$\left(\mathrm{W}_{2}-\mathrm{W}_{1}\right)$

$\left(\ln W_{2}-\ln W_{1}\right) \Delta T^{-1}$

$(\Delta \mathrm{W} / \Delta \mathrm{A}) \times\left(\ln \mathrm{A}_{2}-\ln \mathrm{A}_{1}\right) \Delta \mathrm{T}^{-1}$

$\mathrm{R} \times \mathrm{W}^{-1}$

$\mathrm{S} \times \mathrm{A}^{-1}$ 
T able 2. R esults of the plant-growth analysis of dwarf wheat plants produced after $12 \mathrm{~d}$ of growth on the porous tube (PT ), phenolic foam (PF), or agar gel (AG) systems.,

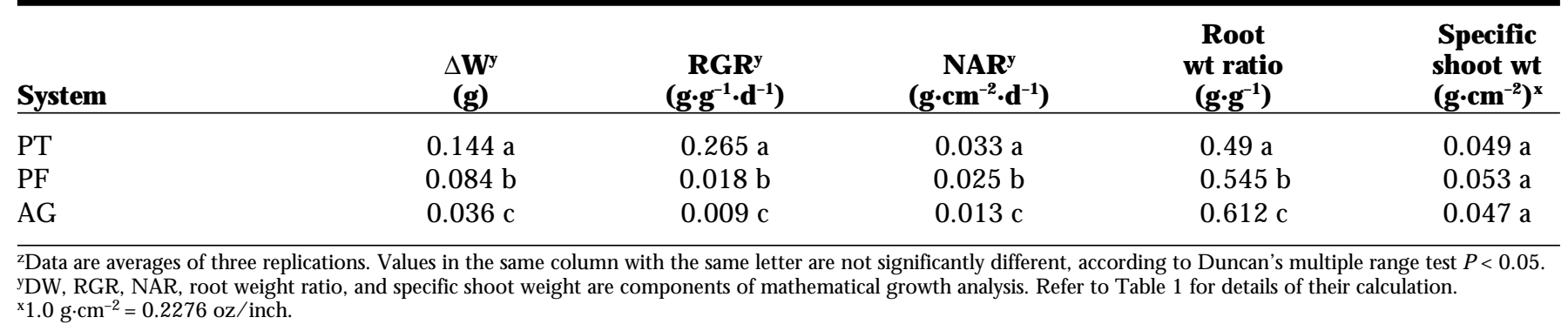

T able 3. R esults of the plant-growth analysis of Brasica rapa plants produced after $12 \mathrm{~d}$ of growth on the porous tube (PT), phenolic foam (PF), or agar gel (AG ) systems. ${ }^{z, y}$

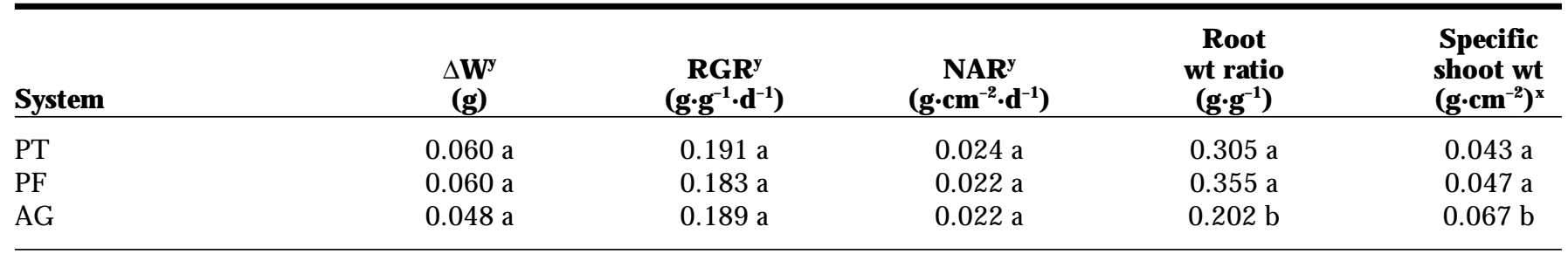

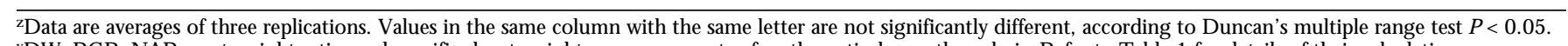
yDW, RGR, N AR, root weight ratio, and specific shoot weight are components of mathematical growth analysis. Refer to Table 1 for details of their calculation.

${ }^{\mathrm{x}} 1.0 \mathrm{~g} \cdot \mathrm{Cm}^{-2}=0.2276 \mathrm{oz} / \mathrm{inch}$.

analysis. The tissue was first degraded by mixing $0.5 \mathrm{~g}$ of dried, ground tissue with $10 \mathrm{~mL}(0.34 \mathrm{fl} \mathrm{oz})$ of a $70 \%$ nitric acid solution and was microwaved for $20 \mathrm{~min}$ at $650 \mathrm{~W}$. N ext, $2 \mathrm{~mL}(0.07 \mathrm{fl}$ oz) of a $37 \%$ hydrochloric acid solution was added and the mixture was microwaved for $5 \mathrm{~min}$ at $650 \mathrm{~W}$. The resulting solution was then diluted with distilled water to $200 \mathrm{~mL}$ (6.76 fl oz) and analyzed using an inductively coupled plasma spectrometer (model
PS-3000; L eeman Labs, I nc., H udson, N.H.).

\section{Results}

The plant-growth analysis data suggest that for dwarf wheat the PTPNDS provided a better environment for plant growth, followed by the phenolic foam and agar gel systems, respectively ( $T$ able 2 ). T his was most evident in the relative growth rates (RGRs) and net assimilation rates
(NARs), which indicate that some environmental stress associated with the agar and phenolic foam systems may have contributed to these differences. The root weight ratiossuggest that the stress responsible for the changes in plant growth affected the allocation of reso urces between the root system and the rest of the plant.

In rapid-cycling brassica, plantgrowth analysis (Table 3) showed that therewerestatistical differencesamong

Table 4. Alcohol dehydrogenase (ADH) activity and protein concentrations in dwarf wheat roots grown for $12 \mathrm{~d}$ on the porous tube (PT), phenolic foam (PF), and agar gel (AG) systems. ${ }^{2}$

\begin{tabular}{|c|c|c|c|}
\hline Sample & $\begin{array}{c}\text { ADH activity } \\
\left(\mathrm{ng} \cdot \mathrm{min}^{-1} \cdot \mathrm{mg}^{-1} \text { protein }\right)^{y}\end{array}$ & $\begin{array}{c}\text { ADH activity } \\
\text { (ng·min }{ }^{-1} \cdot \mathrm{mg}^{-1} \text { fresh wt) }\end{array}$ & $\begin{array}{c}\text { Protein concn } \\
\left(\mu \mathrm{g} \cdot \mathbf{m g}^{-1} \text { fresh } \mathbf{w t}^{w}\right) \\
\end{array}$ \\
\hline PT & $1.625 \pm 0.11 \mathrm{a}$ & $0.131 \pm 0.009 a$ & $80.779 \pm 2.19 a$ \\
\hline$A G$ & $53.881 \pm 3.31 c$ & $2.602 \pm 0.396 c$ & $40.829 \pm 5.43 b$ \\
\hline
\end{tabular}

Table 5. Alcohol dehydrogenase (ADH) activity and protein concentrations in rapid-cycling brassica roots grown for $12 \mathrm{~d}$ on the porous tube (PT), phenolic foam (PF), and agar gel (AG ) systems. ${ }^{2}$

\begin{tabular}{|c|c|c|c|}
\hline Sample & $\begin{array}{c}\text { ADH activity } \\
\left.\text { (ng } \cdot \mathrm{min}^{-1} \cdot \mathrm{mg}^{-1} \text { protein }\right)^{y}\end{array}$ & $\begin{array}{c}\text { ADH activity } \\
\text { (ng. } \mathrm{min}^{-1} \cdot \mathrm{mg}^{-1} \text { fresh wt) }\end{array}$ & $\begin{array}{c}\text { Protein concn } \\
\left(\mu \mathrm{g} \cdot \mathrm{mg}^{-1} \text { fresh } w t^{w}\right)\end{array}$ \\
\hline PT & $29.573 \pm 4.99 a$ & $0.249 \pm 0.019 a$ & $8.443 \pm 4.72 \mathrm{a}$ \\
\hline$A G$ & $731.234 \pm 28.87 b$ & $3.457 \pm 0.295 b$ & $4.728 \pm 2.18 b$ \\
\hline
\end{tabular}

${ }^{z}$ All values are averages \pm SE $(n=3)$.V alues in the same column with the same letter are not significantly different, according to $D$ uncan's multiple range test $P<0.05$. $\mathrm{y} 1 \mathrm{ng} \cdot \mathrm{min}^{-1} \cdot \mathrm{mg}^{-1}=10^{-6} \mathrm{oz} / \mathrm{min} / \mathrm{Oz}$.

${ }^{\mathrm{x}} \mathrm{l \textrm {mg }} \cdot \mathrm{mg}^{-1}=10^{-3} \mathrm{oz} / \mathrm{oz}$. 


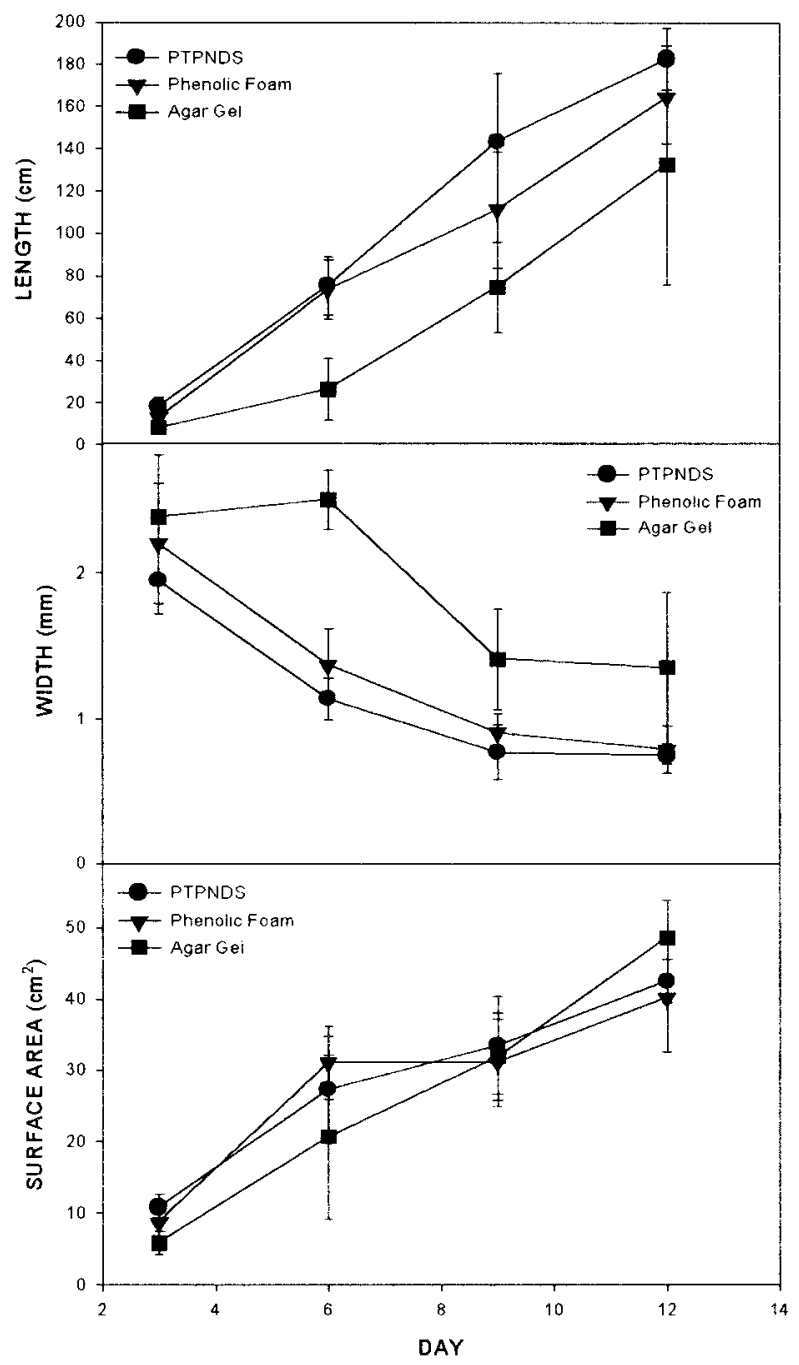

Fig. 5. Comparison of morphometric changes associated in dwarf wheat roots grown on the three nutrient delivery systems for $\mathbf{1 2} \mathrm{d}$. For conversions, $2.54 \mathrm{~cm}=1.0$ inch; 25.4 $\mathrm{mm}=1.0$ inch; $6.45 \mathrm{~cm}^{2}=1.0$ inch $^{2}$.

these systems on the basis of the root weight ratios. Significant differences existed between the agar grown plants and both the PTPNDS and the phenolic foam plants. These differences were also evident in the specific shoot weight values.

The results of the ADH assays of $12 \mathrm{~d}$-old dwarf wheat roots show that different metabolic conditions exist in plants grown with the different nutrient delivery systems (Table 4). Significant differences in ADH activity occurred in plant roots grown by these different methods, whether analyzed on the basis of protein or of fresh weight. The roots of plants grown on the agar system contained a very large
AD H activityresponse that was considerably higher than the other two treatments. The phenolic foam system roots exhibited a significantly higher ADH activity ascompared to the porous tube system. In theagar grown plants there was a decrease in root protein concentration levels, while the porous tube and phenolic foam root protein concentration levels did not differ statistically from one another.

In rapid-cycling brassica, the agar gel system was associated with significantly higher levels of ADH activity and decreased protein concentrations (Table 5) when compared to the PTPNDS and the phenolic foam systems. A nalysis of AD H activity and protein concentrations from thePTPNDS and the phenolic foam systemsshowed that there wereno significant differencesbetween these systems.

In general, the root system of germinating wheat seedlings went through a specific set of morphological changes (Fig. 5). The first roots that emerged from a wheat seedling were typically the widest present on the plant during this growth period. The average root width decreased as the total root length increased. These changes in morphology had the effect of increasing the lateral surface area, while minimizing the increase in longitudinal section area. Conceptually thesemorphological changes could be responsible for increasing the surface area available for nutrient and water transport while minimizing the distance through the root that must be traversed before loading into the tracheary elements of the vascular bundle.

During the entire 12-d growth period, no differences in root surface area occurred between treatments despite significant differences in length and width occurring during the same period (Fig. 5). O n day 3, therewasno difference in average root width, but on days 6 to 12 the porous tube and phenolic foam roots were significantly thinner than the agar system roots. Root length displayed a similar trend, with no difference at $3 d$, but by day 6 there were significant differences between the agar system and the other systems. By day 9 and 12 the foam and agar systems did not have significant morphological differences, although the porous tube and agar systems did differ statistically.

Elemental composition analysis showed that there were differences in nutrient composition in dwarf wheat plants grown using the three nutrient delivery systems (Tables 6 and 7). In the shoots and roots, $\mathrm{K}, \mathrm{P}, \mathrm{C}$ a, and $\mathrm{M} \mathrm{g}$ concentrations were different among all of the systems. In the shoots, the concentrations of these nutrients decreased in relation to ADH activity increases while in the roots, the nutrient levels increased, although not uniformly. In the shoots, the PTPNDS had the highest levels of these nutrients and the agar gel system showed the lowest, and in the roots the reverse trend was noted. The agar gel system also showed decreased shoot and increased root levels of $\mathrm{Fe}, \mathrm{S}$, and $\mathrm{Mn}$ compared to the other two systems.

\section{Discussion}

R anking the systems on the basis of ability to support dwarf wheat growth indicates that, during the $12-d$ period, the poroustube nutrient delivery system supported a higher level of plant growth followed by the phenolic foam and agar gel systems respectively (Table 2). This is most evident in the RGR and NAR values based on leaf area and dry tissue weights. The shoot and root weight ratios related to the different nutrient delivery systems indicate that some sort of root zone stress may have been associated with the agar gel and phenolic foam systems.

Plant-growth analysis revealed that there was very little difference between rapid-cycling brassica plants grown using the three systems ( $T$ able 3). There were no changes in the indicators of photosynthetic productivity (RGR and NAR), but there was a change in weight distribution associated with the agar grown plants. In a previous report describing the growth of A rabidopsis thaliana (L.) H eynh. 
T able 6. Elemental composition, as determined by IC P analysis, of dwarf wheat shoots grown for $12 \mathrm{~d}$ on the porous tube (PT), phenolic foam (PF), and agar gel (AG) nutrient delivery systems. ${ }^{2 y}$

\begin{tabular}{|c|c|c|c|c|c|c|c|c|c|c|}
\hline System & $\begin{array}{c}K \\
(\%)\end{array}$ & $\begin{array}{c}P \\
(\%)\end{array}$ & $\begin{array}{c}\text { B } \\
\left(\mu \mathbf{g}^{\prime} \cdot \mathbf{g}^{-1}\right)\end{array}$ & $\underset{\left(\mu \mathbf{g} \cdot \mathbf{g}^{-1}\right)}{Z \mathbf{n}}$ & $\begin{array}{c}\mathbf{F e} \\
\left(\mu \mathbf{g} \cdot \mathbf{g}^{-1}\right)\end{array}$ & $\begin{array}{c}\mathbf{S} \\
(\%)\end{array}$ & $\underset{\left(\mu g \cdot g^{-1}\right)}{C u}$ & $\begin{array}{l}\mathrm{Ca} \\
(\%)\end{array}$ & $\begin{array}{l}\text { Mg } \\
(\%)\end{array}$ & $\begin{array}{c}M \mathbf{n} \\
\left(\mu \mathbf{g} \cdot \mathbf{g}^{-1}\right)\end{array}$ \\
\hline PT & $\begin{array}{l}1.93 a \\
\pm 0.37\end{array}$ & $\begin{array}{c}0.490 \text { a } \\
\pm 0.04\end{array}$ & $\begin{array}{c}73.3 a \\
\pm 6.3\end{array}$ & $\begin{array}{c}35.9 \mathrm{a} \\
\pm 3.4\end{array}$ & $\begin{array}{l}166 \mathrm{a} \\
\pm 9.3\end{array}$ & $\begin{array}{c}0.361 \mathrm{a} \\
\pm 0.03\end{array}$ & $\begin{array}{l}10.9 a \\
\pm 0.56\end{array}$ & & & $\begin{array}{c}50.8 \mathrm{a} \\
\pm 8.1\end{array}$ \\
\hline PF & $\begin{array}{l}1.26 \mathrm{~b} \\
\pm 0.22\end{array}$ & $\begin{array}{c}0.232 \mathrm{~b} \\
\pm 0.02\end{array}$ & $\begin{array}{c}71.0 \mathrm{a} \\
\pm 1.9\end{array}$ & $\begin{array}{c}33.9 \mathrm{a} \\
\pm 2.9\end{array}$ & $\begin{array}{l}157 a \\
\pm 10.8\end{array}$ & $\begin{array}{c}0.370 a \\
\pm 0.04\end{array}$ & $\begin{array}{l}10.1 \mathrm{a} \\
\pm 0.98\end{array}$ & $\begin{array}{c}0.464 \mathrm{~b} \\
\pm 0.19\end{array}$ & $\begin{array}{c}0.285 \mathrm{~b} \\
\pm 0.22\end{array}$ & $\begin{array}{c}51.9 \text { a } \\
\pm 5.3\end{array}$ \\
\hline AG & $\begin{array}{l}0.86 \mathrm{c} \\
\pm 0.19\end{array}$ & $\begin{array}{c}0.125 \mathrm{c} \\
\pm 0.03\end{array}$ & $\begin{array}{c}88.3 a \\
\pm 9.0\end{array}$ & $\begin{array}{c}32.6 \mathrm{a} \\
\pm 4.6\end{array}$ & $\begin{array}{c}93 \mathrm{~b} \\
\pm 14.3\end{array}$ & $\begin{array}{c}0.274 \mathrm{~b} \\
\pm 0.04\end{array}$ & $\begin{array}{l}28.9 a \\
\pm 2.34\end{array}$ & $\begin{array}{c}0.165 \mathrm{c} \\
\pm 0.07\end{array}$ & $\begin{array}{l}0.090 \mathrm{C} \\
\pm 0.05\end{array}$ & $\begin{array}{c}22.9 \mathrm{~b} \\
\pm 5.9\end{array}$ \\
\hline
\end{tabular}

${ }^{z}$ All values are averages \pm se $(n=3)$.Values in the same column with the same letter are not significantly different, according to $D$ uncan's multiple range test $P<0.05$. y $1 \mathrm{mg} \cdot \mathrm{g}^{-1}=1 \mathrm{ppm}$.

T able 7. Elemental composition, as determined by IC $P$ analysis, of dwarf wheat roots grown for $12 \mathrm{~d}$ on the porous tube (PT), phenolic foam (PF), and agar gel (AG) nutrient delivery systems. ${ }^{2 y}$

\begin{tabular}{|c|c|c|c|c|c|c|c|c|c|c|}
\hline System & $\begin{array}{c}K \\
(\%)\end{array}$ & $\begin{array}{c}P \\
(\%)\end{array}$ & $\begin{array}{c}\text { B } \\
\left(\mu \mathbf{g} \cdot \mathbf{g}^{-1}\right) \\
\end{array}$ & $\begin{array}{c}Z \mathbf{n} \\
\left(\mu \mathbf{g}^{-1} \mathbf{g}^{-1}\right)\end{array}$ & $\begin{array}{c}\mathbf{F e} \\
\left(\mu \mathrm{g} \cdot \mathbf{g}^{-1}\right)\end{array}$ & $\begin{array}{c}\mathbf{S} \\
(\%)\end{array}$ & $\begin{array}{c}\mathrm{Cu} \\
\left(\mu \mathrm{g} \cdot \mathbf{g}^{-1}\right)\end{array}$ & $\begin{array}{l}\mathrm{Ca} \\
(\%)\end{array}$ & $\begin{array}{l}\mathrm{Mg} \\
(\%)\end{array}$ & $\begin{array}{c}M \mathbf{n} \\
\left(\mu \mathbf{g}^{-1}\right)\end{array}$ \\
\hline PT & $\begin{array}{c}0.162 \mathrm{a} \\
\pm 0.02\end{array}$ & $\begin{array}{c}0.181 \text { a } \\
\pm 0.02\end{array}$ & $\begin{array}{c}59.3 \mathrm{a} \\
\pm 8.6\end{array}$ & $\begin{array}{c}167.5 \mathrm{a} \\
\pm 19.8\end{array}$ & $\begin{array}{l}674 a \\
\pm 48\end{array}$ & & & & & $\begin{array}{c}483.3 \mathrm{a} \\
\pm 35.7\end{array}$ \\
\hline PF & $\begin{array}{c}0.132 \mathrm{~b} \\
\pm 0.01\end{array}$ & $\begin{array}{c}2.195 \mathrm{~b} \\
\pm 0.48\end{array}$ & $\begin{array}{c}63.8 \mathrm{a} \\
\pm 2.9\end{array}$ & $\begin{array}{c}157.5 \mathrm{a} \\
\pm 22.1\end{array}$ & $\begin{array}{c}658 \text { a } \\
\pm 37\end{array}$ & $\begin{array}{c}0.793 \mathrm{a} \\
\pm 0.04\end{array}$ & $\begin{array}{l}29.8 a \\
\pm 4.59\end{array}$ & $\begin{array}{l}2.25 b \\
\pm 0.31\end{array}$ & $\begin{array}{c}0.125 \mathrm{~b} \\
\pm 0.03\end{array}$ & $\begin{array}{c}443.5 \mathrm{a} \\
\pm 29.6\end{array}$ \\
\hline$A G$ & $\begin{array}{c}0.109 \mathrm{c} \\
\pm 0.02\end{array}$ & $\begin{array}{c}5.773 \mathrm{c} \\
\pm 0.83\end{array}$ & $\begin{array}{c}64.8 \text { a } \\
\pm 7.4\end{array}$ & $\begin{array}{c}148.3 \text { a } \\
\pm 25.4\end{array}$ & $\begin{array}{c}3012 \mathrm{~b} \\
\pm 34\end{array}$ & $\begin{array}{c}2.674 \mathrm{~b} \\
\pm 0.41\end{array}$ & $\begin{array}{l}33.8 \mathrm{a} \\
\pm 7.89\end{array}$ & $\begin{array}{l}2.94 \mathrm{C} \\
\pm 0.39\end{array}$ & $\begin{array}{c}0.280 \mathrm{C} \\
\pm 0.04\end{array}$ & $\begin{array}{c}1592.9 \mathrm{~b} \\
\pm 72.5\end{array}$ \\
\hline
\end{tabular}

${ }^{z}$ All values are averages \pm SE $(n=3)$.V Values in the same column with the same letter are not significantly different, according to $D$ uncan's multiple range test $P<0.05$.

y1 $\mathrm{mg} \cdot \mathrm{g}^{-1}=1 \mathrm{ppm}$.

on an agar medium, Porterfield et al. (1997) used controlled oxygen atmospheres and direct measurement of oxygen status in the root zone to establish that the agar system producesa strongly hypoxic root zone compared to typical soil culture. Furthermore, the enzyme ADH could be used as an indicator of how hypoxic the medium was, since activity increased linearly as oxygen availability decreased (Porterfield et al., 1997). In the hypoxic agar medium the rapid-cycling brassica root weight ratio decreased relative to that of the other two systems. This change was due to an increase in the specific shoot weight (Table3) and adecrease in root weight (data not shown). Increased specific leaf weight has been described previously for waterlogged brassica rapa, and was attributed to starch accumulation in the foliage due to diminished root metabolism (Daugherty and M usgrave, 1994).

The increase in ADH activity (Table 4) associated with the dwarf wheat plants grown on the agar gel and phenolic foam systems complementsour previous results (Porterfield et al., 1997) and strongly suggests that low oxygen root conditions existed within these systems. O ther indicators of low oxygen root conditions in these plantswerethemorphological changes (Fig. 5). Thesechanges are most probably a response to differing levels of oxygen availability associated with the different systems, since it has been shown that under oxygen-limited conditions roots are shorter and thicker (Waddington and Baker, 1965; U nger and D anielson, 1965). R apid-cycling brassica plants grown in the agar system also exhibited an increase in AD H activity (Table 5) signifying that there were problems of oxygen availability to the roots in the system. H owever, plant-growth analysis data and previousstudies( $D$ aughertyand M usgrave, 1994) suggest that rapid-cycling brassica is more tolerant of a low oxygen root environment than is dwarf wheat during early growth. In fact, rapidcycling brassica can be grown by static or nonaerated hydroponic culture (H ershey, 1992). The ADH response in rapid-cycling brassica is also associated with a decrease in root mass, which is analogous to the changes in root morphology seen in the dwarf wheat experiments.

Elemental composition analysis indicated that these systems differ in their ability to provide nutrients to plants (T ables 6 and 7). Decreases in shoot nutrient content corresponded with increases in root nutrient levels and $\mathrm{ADH}$ activity. Since identical nutrient solutions were used in these experiments, differences in nutrient content may betheresult of changes in the metabolic status of roots grown in the different systems. L ow oxygen conditions are known to decrease adenylateenergy charge (Saglio et al., 1980) and $\mathrm{H}+/$ ATPase (proton/ adenosine triphosphatase) activity (Poole, 1978) levels in roots. The chemiosmotic gradient and themembrane potential that result from proton pumping are believed to be the driving forces for nutrient uptakein plant roots (C heeseman and $\mathrm{H}$ anson, 1979; Saglio et al. 1980). $\mathrm{N}$ umerous studies have noted that decreased nutrient uptake is a consequence of a reduction in oxygen availability to the roots ( $\mathrm{H}$ opkins et al., 1950; Leyshon and Sheard, 1974; Trought and Drew, 1980; Trought and $D$ rew, 1981). D ing and $M$ usgrave (1995) found changes in root-system nutrient content similar to these results (increased $\mathrm{Fe}, \mathrm{Mn}$, and $\mathrm{P}$ ) that also related to the appearance of insolublemineral complexeson theroots grown under waterlogged conditions.

N one of thebiochemical and morphological changestypicallyassociated with diminished oxygen availability was found in the plants grown on the porous tube system. This absence might 
explain the striking differences in plant growth and nutrient uptake measured in the dwarf wheat grown on the PT PND S compared to the other systems. Since the roots are directly in contact with both the nutrient-delivering porous tube and the air space contained between the tube and the polyethylene tube wrap, the porous tubesystem apparently provides greater oxygen availability. This may prove to beamajor advantage in thespaceflight environment because of the evidence that plant root systems respond biochemically to decreased oxygen availability during exposure to spaceflight (Porterfield et al., 1997). I n the dwarf wheat experiments, phenolic foam grown plantstended to perform better than agar grown plants but exhibited some morphological and biochemical signs of hypoxic stress after $6 \mathrm{~d}$. This may be due to the fact that the relatively large root mass was contained in a very small space by the $\mathrm{N}$ itex envelope.

The agar system appears to be analogousto static hydroponic culture in that it produces morphological and biochemical responses in dwarf wheat similar to those produced by hypoxia. While this system has been used to support short term plant growth experiments in space ( $\mathrm{H}$ eyenga, 1994; Kordyum et al., 1983; Kuang et al., 1995), its use in long-term studies undertaken aboard a space station should be avoided if an alternative is available (for experiments using dwarf wheat or other flood intolerant species).

\section{Literature cited}

Cheeseman, J.M . and J.B. H anson. 1979. Energy linked potassium influx as related to cell potential in corn roots. Plant Physiol. 64:842-845.

Cowles J.R., H.W. Scheld, R. Lemay, and C. Peterson. 1984. Growth and lignification in seedlings exposed to eight days of microgravity. Ann. Bot. 54(3):33-49.

D augherty C.J . and M .E. M usgrave. 1994. Characterization of populations of rapidcycling Brassica rapa L. selected for differential waterlogging tolerance. J. Expt. Bot. 45:385-392.

Ding N . and M .E. M usgrave. 1995. Relationship between mineral coating on roots and yield performance of wheat under waterlogging stress. J. Expt. Bot. 46:939945.
D reschel T.W., C.F. Johnson, C.W. Carson, H.W. Wells, E.J. Wiegrefe, C.S. Brown, W.M. Knott, and W. M unsey. 1994. The microgravity plant nutrient experiment: Finalizing the design for a fall 1995 flight opportunity. Amer. Soc. G ravitational Space Biol. Bul. 8(1):77.

H alstead T.W. and F.R. Dutcher. 1984. Status and prospects. In: Experiments on plant growth in space. Ann. Bot. (Suppl.) 54:3-18.

H ershey D.R. 1992. Culturing brassica by hydroponics. C arolina Tips 55(1):1-3.

H eyenga A.G. 1994. Application of a water replenished solidified nutrient media support system in long term cultivation of wheat. Amer. Soc. G ravitational SpaceBiol. Bul. 8(1):40.

Hoagland D.R. and D.I. Arnon. 1950. The water culture method for growing plants without soil. Calif. Agr. Expt. Sta. Circ. 347:1-32.

Hopkins H.T., A.W. Specht, and S.B. $\mathrm{H}$ endricks. 1950. Growth and nutrient accumulation ascontrolled by oxygen supply to plant roots. Plant Physiol. 25:193209.

Johnson C.F., T.W. D reschel, C.S. Carlson, and C.S. Brown. 1995. Analysis of water imbibition for the microgravity plant nutrient experiment on the KC-135. Amer. Soc. Gravitational Space Biol. Bul. 9:48.

Kordyum E.L., I.F. Chernyaeva, I.D. Anikeeva, and E.N. Vaulina. 1983. Characteristics of generative phase of development in A rabidopsisthaliana plants under spaceflight conditions. O ntogenez 14(2):186-194.

Krikorian A.D. and H.G. Levine 1992. Effects of spaceflight on growth and cell division in higher plants. Adv. Space Biol. M edicine 2:181-209.

Kuang A., M .E. M usgrave, S.W. M atthews, D.B. Cummins, and S.C. Tucker 1995. Pollen and ovule development in A rabi dopsisthaliana under spaceflight conditions. Amer. J. Bot. 82(5):585-595.

Levine H.G. and A.D. Krikorian. 1992. Chromosomes and plant cell division in space: Environmental conditions and experimental details. Adv. Space Res. 12:7382.

Leyshon A.J. and R.W. Sheard. 1974. Influence of short-term flooding on the growth and plant nutrient composition of barley. Can. J. Soil Sci. 54:463-473.

M arkwell M.A.K., M.H. Suzanne, L.L. Bieber, and N.E. Tolbert. 1978. A modification of the L owry procedureto simplify protein determination in membrane and lipoprotein samples. Anal. Biochem. 87:206-210.
Pan W.L. and R.P. Bolton. 1991. Root quantification by edge discrimination using a desktop scanner. A gron. J. 83:10471052.

Poole R.J. 1978. Energy coupling for membrane transport. Annu. Rev. Plant Physiol. 29:437-460.

Porterfield, D.M., S.W. M atthews, C.J. Daugherty, and M.E. M usgrave. (1997) Spaceflight exposure effects on transcription, activity, and localization of alcohol dehydrogenase in the roots of $A$ rabidopsis thaliana. Plant Physiol. 113:685-693.

Saglio P.H ., P. Raymond, and A. Pradet. 1980. M etabolic activity and energy charge of excised maize roots under anoxia. Control by soluble sugars. Plant Physiol. 66:1053-1057.

Trought M.C.T. and M.C. D rew. 1980. The development of water logging damage in wheat seedlings (Triticum a estivum L.) II. Accumulation and distribution of nutrients by the shoot. Plant Soil 56:187199.

Trought M.C.T. and M.C. D rew. 1981. Alleviation of injury to young wheat plants in anaerobic solution culture in relation to the supply of nitrate and other inorganic nutrients. J. Expt. Bot. 32:509-522.

Unger P.W. and R.E. Danielson. 1965. Influence of oxygen and carbon dioxide on germination and seedling development in corn (Zea maysL.). Agron. J. 57:56-63.

Waddington D.V. and J.H. Baker. 1965. Influence of soil aeration on the growth and chemical composition of three grass species. Agron. J. 57:253-256. 